\title{
Um passado que somos: sobre Casa-grande e Senzala pela voz de Fernando Nicolazzi
}

\author{
A Past We Are: about Casa-grande e Senzala through the Voice of \\ Fernando Nicolazzi
}

NICOLAZZI, Fernando. Um estilo de História: a viagem, a memória, o ensaio: sobre Casa-grande e Senzala e a representação do passado. São Paulo: Editora UNESP, 2011. 486 p.

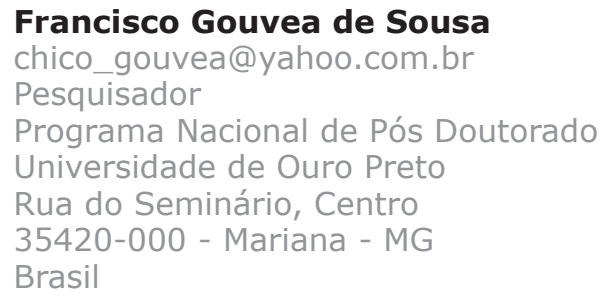

Palavras-chave

Ensaio; Gilberto Freyre; Historiografia brasileira.

Keywords

Essay; Gilberto Freyre; Brazilian historiography. 
Não faz muito tempo, um amigo iniciava sua defesa de doutorado com a seguinte questão: por que ler esta tese e não ler diretamente Machado de Assis? Ao longo da apresentação de Daniel Pinha, ficava claro que a questão era mais difícil do que poderia parecer inicialmente, pois o problema não era apenas a monumental fortuna crítica que Machado de Assis impõe, nem a força de sua obra; mas a dificuldade em dispor de conceitos pelos quais se possa falar de como o passado nos constitui. Mais do que se interessar apenas em como se posicionar em relação a Machado de Assis, interessa expor como Machado de Assis se posicionava em relação ao seu próprio passado em sua crítica literária. Assim, especialmente em Notícia atual da literatura brasileira: instinto de nacionalidade (1873), o conceito de pecúlio ganha destaque e centralidade, pois é justamente um meio para expor a presença das produções do passado que nos constituem. É um artifício da crítica machadiana incorporada à compreensão do próprio Machado de Assis. A postura, formada por esta compreensão de que somos formados por heranças, fica exposta da seguinte forma: "Trata-se de uma decisão que implica o aproveitamento crítico do que essa tradição pode ter deixado de herança positiva [...] e, ao mesmo tempo, significa a decisão de romper com o instinto de modernidade, entendido como eterno recomeço do presente" (SILVA 2012, p. 74).

A questão, assim, tem duas direções: não só o passado está em nós, como a busca incessante pela ruptura apenas nos faz insensíveis a sua presença. A 266 arrogância que às vezes assumimos no tempo presente - seja pelo elogio ao novo e ao atualizado ou, em sua forma mais radical, à originalidade como conquista de um "eu", como se ideais e textos fossem consequências de uma produção estritamente individual - apenas obscurece a presença do passado em nós, o que não diminui, porém, sua força. Saibamos disto ou não, somos movidos por heranças.

Falar de pecúlio, pelo menos nesta resenha, é uma forma de se dirigir a esse passado que está em nossa formação, um passado em movimento, revivido e reconstruído. Falar de pecúlio permite iniciar a resenha de um livro que tem por estímulo Casa-grande e Senzala já adiantando que tal livro não pretende uma visão estática da obra de Gilberto Freyre; pelo contrário, ela mesma tem seu pecúlio, sua fortuna crítica que pode ser exposta como história.

Começar a resenha do livro de Fernando Nicolazzi Um estilo de história produto de sua tese defendida na Universidade Federal do Rio Grande do Sul (UFRGS) sob a orientação de Temístocles Cezar - por essa lembrança tem dois sentidos. O primeiro e mais óbvio: por que ler esta resenha? Afinal, se considero que o livro é interessante, única razão para resenhá-lo, por que não apenas lêlo? O segundo diz sobre o próprio livro em questão: mas, afinal, por que mais produção sobre Casa-grande e Senzala (CG\&S)? Essa resposta já foi dada pela lembrança, mas é preciso calma e alguma prudência.

Sobre a primeira pergunta, ao leitor da resenha ofereço um pequeno roteiro para o livro, assim como as indicações de praxe sobre algumas das questões discutidas pelo autor. Espero que do roteiro um possível leitor que já conheça o livro possa tirar algum proveito. 
A segunda pergunta pode ser respondida diretamente com uma afirmação: o livro de Fernando Nicolazzi não é um novo trabalho sobre Casa-grande e Senzala; essa obra é apenas um dos meios do livro, um dos elementos pelo qual o livro se realiza. O assunto principal da obra de Nicolazzi me parece ser um pecúlio, um passado composto por diferentes produções que nos constitui e que o autor apresenta, discute e, principalmente, coloca em movimento por questões próprias do presente. Destaco, apenas para ilustrar esse ponto, toda uma discussão que inicia o livro sobre a dimensão literária da obra de Freyre.

Autores como Hayden White - e a partir dele a discussão se multiplicou têm chamado a atenção para a possibilidade de pensar uma dimensão literária do texto historiográfico. Nicolazzi, ao mesmo tempo em que expõe o debate teórico, não se limita a ele. A teoria não fica fora ou deslocada do objeto. Seu leitor é exposto ao debate como se este estivesse vivo e em movimento a sua frente. Essa impressão é produzida pelo modo em que o texto se forma pelo contato com um conjunto variado de elementos, como as recepções da obra de Gilberto Freyre - seus leitores críticos - ou os próprios prefácios que o autor ia produzindo num diálogo com essas recepções. Nesse movimento, questões do presente como a dimensão literária da escrita da história - são perpassadas por questões do passado. É interessante como nesse jogo entre recepções críticas, por vezes, CG\&S era admirada por sua acuidade científica e se lamentava por seus excessos literários; em outros casos, a recepção crítica apontava justamente o inverso. Fica claro que essa tensão entre escrita científica e escrita literária está longe de ser uma novidade; é na verdade um pecúlio, compõe o passado que herdamos e que está presente em nossa formação. Assim, se existe atualidade no livro, ele também está repleto de questões caras a diferentes passados. O texto é, nesse sentido, necessariamente dialógico. A forma de construção dos argumentos pode ser exposta nesta direção: debates do presente são apresentados e postos em movimento por questões que, desde a sua publicação, CG\&S tem levantado. É um diálogo constante entre passado e presente sem hierarquia entre as partes.

Assim, ao chegar aos temas viagem e memória - partes fundamentais do terceiro capítulo -, o leitor pode se ver frente aos Antigos e, simultaneamente, ao presente. Existe um "nós" constante no livro de Nicolazzi; ele é progressiva e lentamente construído, é um "nós" que se expande pelo pecúlio que o autor mobiliza e nos dispõe, expondo-nos simultaneamente a ele (o que me parece ser a virtude principal do livro). O passado não é visto pela lente arrogante da análise que se supõe autônoma em relação ao objeto que investiga, mas pela audição de quem quer saber o que ele (o passado) pôde dizer e ainda diz.

A partir dessa imagem, indo para o roteiro e assumindo o direito de interferir na leitura, sugiro um momento inicial específico: a seção "uma retórica da identidade" (NICOLAZZI 2011, p. 351-371). Neste momento aparece uma questão que mobiliza o livro quase que por inteiro, mas aqui está clara. Estas palavras a sintetizam: 
contato com seu objeto, acaba por instituir o antes e o depois como uma separação abrupta entre a presença e a ausência, aquilo que cria a distinção inevitável, pela instituição dos arquivos, entre sujeito e objeto, entre discurso e experiência, criando entre ambos um espaço de mediação e não de imediatismo. Essa fronteira transposta, no caminho que segue do mediado até o imediato, permitiria a ele manter com o passado uma relação mais intensa, tocando-Ihe os nervos como se ele estivesse ali, ao alcance das mãos (e dos olhos) (NICOLAZZI 2011, p. 330).

É nesse sentido que o livro não é sobre Gilberto Freyre, nem sobre Casa-grande e Senzala, mas sobre o que somos, sobre que estilos e verdades herdamos. A problematização da separação entre o presente e o passado, entre história e memória, é, assim, fundamental. Como diria Paul Ricouer, referência importante para Nicolazzi, "A distância é um fato. O distanciamento é um comportamento metodológico" (RICOEUR 2011, p. 124). A pergunta pelo estilo nasce de um interesse por dar alguma maleabilidade a esse "comportamento". O mesmo se pode dizer sobre a forma ensaio, objeto fundamental para o livro.

o ensaio é, inclusive, um pecúlio que podemos acessar apenas indiretamente; pois a "nós" é permitido mais estudá-lo do que escrevê-lo. Talvez seja o desejo de (re)habilitar o ensaio um dos motivos do livro, o que não deve ser resumido a um desejo do autor. Como bem argumenta Nicolazzi dialogando diretamente com Foucault - o autor não é uma condição prévia da obra, mas um resultado dela, nasce de um passado e se constrói pela ação ativa de diferentes personagens.

Nesse sentido, não sem razão, Os sertões aparece como uma espécie de contraponto espesso à Casa-Grande e senzala no segundo capítulo do livro resenhado. Nicolazzi assume a leitura densa de Os Sertões como caminho para dar visibilidade ao horizonte de produção de Casa-grande e Senzala. Se todo historiador da segunda metade do Oitocentos teve de lidar com a condição de escrever depois da publicação da História geral do Brasil de Varnhagen (pergunte a Capistrano de Abreu o peso dessa condição), Gilberto Freyre teve de lidar com a escrita do Brasil colônia como se fosse presente, teve de escrever depois de Os sertões, que, pela viagem e confronto, atestava que o passado estava logo ali, bastava ir. Os sertões é o resultado de uma viagem feita por um letrado que representava a civilização e que foi ao encontro do sertão, do não civilizado. Se o território que compunha a nação era uma unidade, era uma unidade heterogênea, e o que definia a distância entre cada uma de suas partes era a própria temporalidade. Na narrativa da viagem de Euclides da Cunha, fica claro um clima de dissonância entre diferentes tempos, como se o sertão vivesse num outro tempo que nunca chegava à civilização, que talvez desconhecesse totalmente a ação do tempo. Ir para o sertão era, assim, viajar para o passado.

Se a obra de Euclides da Cunha narra esse encontro entre tempos distintos, os sertões parecem desconhecer o progresso e zombar dele - afinal quando o progresso "chega" os sertões resistem. Se essa é uma das questões que aparecem na relação entre narrativa e tempo em Os sertões, Casa-grande e Senzala tem por marca um tempo homogêneo que se realiza como passado do 
presente e futuro do presente - algo que se explicará a seguir. A discussão sobre Os sertões, assim, não é apenas sobre o horizonte no qual CG\&S foi publicado, pois ela prepara também a discussão teórica - pela própria hermenêutica da obra de Euclides da Cunha - necessária para a discussão que Nicolazzi se propõe a fazer em relação a CG\&S.

Depois de toda a discussão feita sobre Os sertões, o ponto principal de onde parte a imagem do tempo homogêneo - a temporalidade própria de CG\&S - é a leitura que Paul Ricoeur faz de Santo Agostinho. Essa temporalidade seria marcada por uma consciência aguda de que o futuro e o passado acontecem no presente e de que o próprio presente acontece por eles, especialmente no que diz respeito à escrita sobre o passado.

[...] escrever o passado é escrever o que foi visto e o que ainda se vê, mesmo que por olhos de outrem; é torna-lo, uma vez mais, algo presente e vivo, ressuscitado pelo texto que representa o próprio passado. [...] É como se aquilo que ele visse, na medida mesma em que é visto, de fato existisse (NICOLAZZI 2011, p. 322).

Esta discussão sobre a temporalidade própria de CG\&S reafirma o que acredito ser uma das questões mais interessantes do livro: fazer-nos pensar sobre o que implica assumirmos como aporia a distinção rígida entre história e memória e o que ocorre quando fazemos isso. Nesse sentido, sugiro a leitura, em seguida, do momento do livro sobre as relações entre tempo e narrativa em Os sertões e em Casa-grande e Senzala na medida em que é possível produzir uma conversa entre esses momentos do livro. A análise de Os sertões está no segundo capítulo, como já tinha comentado, e a seção sobre tempo e narrativa em Casa-grande e Senzala se inicia com o título de "Tempo homogêneo". Dessa conversa fica claro o quanto o tema da temporalidade pode ampliar nossa compreensão sobre o quanto a separação rígida entre história e memória, consequência de ter o distanciamento como opção metodológica, apenas nos torna menos sensíveis à presença do passado, ao pecúlio que compõe nossa formação. Muitos são os momentos em que escrever e ler sobre o passado é estar com ele. O distanciamento apenas nos dessensibiliza. Pensar temporalidades distintas e próprias, pelo contrário, abre-nos ao passado.

No primeiro capítulo, Nicolazzi lida com os diferentes prefácios e recepções de Casa-grande e Senzala, o que foi comentado parcialmente. O pecúlio é o início do livro; um pecúlio construído pelas vozes que leram a obra e pela própria voz de Gilberto Freyre intervindo no debate, especialmente por seus novos prefácios. Neste meio, Casa-grande e Senzala é um instrumento de definição de campos e de saberes, de acertos e de erros. Os debates oscilavam sistematicamente entre elogiar os traços literários da obra e lamentar suas imprecisões científicas ou, pelo contrário, elogiar a precisão científica e lamentar os excessos literários. Essas divergências dizem muito sobre o que somos. A necessidade de nos afirmarmos ciência, se garante uma via institucional, talvez nos separe de um universo mais amplo de leitores. A defesa de um espaço institucional para a história parece cobrar o 
preço de nos limitarmos a ele. Ter CG\&S como pecúlio reafirma essa tensão, constrange nossas escolhas. Tal tensão emerge, certamente, no contato com essa tradição ensaística que extrapolou os limites e fronteiras de um campo científico e ainda o extrapola.

Nessa direção, por fim, existe uma questão que, por estilo e escolha, não aparece de forma direta mas como provocação, e assumo como último comentário nesta resenha trazê-la à tona. Em meio a uma discussão sobre o olhar de Gilberto Freyre e a relação desse olhar como constitutivo do estilo de Casa-grande e Senzala, quando começa a ficar claro que o uso do testemunho do próprio autor vai além de uma estratégia de convencimento, de confirmação de que Gilberto Freyre estaria apto a dizer o que diz ("vai além" na medida em que integra o estilo justamente na direção de transpor a dicotomia história e memória), justo nesse momento no qual o leitor descobre uma relação íntima e intensa entre Gilberto Freyre, seu passado e Casa-grande e Senzala, aparece um "nós". Esse "nós", mesmo quando observa o mundo de formas variadas, parece estar num mesmo lugar. O lugar de que se olha ainda parece ser a sacada antiga e ao mesmo tempo presente, uma ruína que nos constitui. A casa-grande se revela um pecúlio constrangedor. A última pergunta não é sobre a forma, conteúdo ou meio (que no caso do livro é o estilo), mas sobre a perspectiva. A última pergunta é: quem é esse "nós" que vê o mundo da casa-grande? o que fazemos desse mundo ao vê-lo da sacada?

\section{Referências bibliográficas}

RICOEUR, Paul. Crítica das ideologias. In: . Hermenêutica e ideologias. Petrópolis: Vozes, 2011, p. 107-158.

SILVA, Daniel Pinha. Apropriação e recusa: Machado de Assis e o debate sobre a modernidade brasileira na década de 1870. Tese (Doutorado em História). Programa de Pós-Graduação em História Social da Cultura, Pontifícia Universidade Católica do Rio de Janeiro, Rio de Janeiro, 2012. 